Laboratorio de Arte, 6-1993 http://dx.doi.org/10.12795/LA.1993.i06.18

\title{
PEDRO DE PERALTA Y LAS SARGAS DEL CARNAVAL DE 1732 EN LOS ALCÁZARES DE SEVILLA
}

\author{
POR José María Morillas AlCÁZar
}

\section{LA PINTURA DE SARGAS}

La llamada pintura de sargas es uno de los capítulos más interesantes de la Historia del Arte sevillano. Su análisis se encuadra dentro de las últimas tendencias investigadoras; y, por sus características intrínsecas, se asocia al estudio de la fiesta. Esta manifestación pictórica se realiza para exornar arquitecturas efímeras o permanentes y decorados perecederos.

La pintura, por definición, es la aplicación de pigmentos o colores, al temple o al óleo, sobre una determinada superficie. En el caso de la pintura de sargas, esta superficie estaría formada por una tela cuya trama formaría líneas diagonales. El carácter y su duración eran perecederos y su función principal sería el exorno temporal, adquiriendo intrínsecamente un sentido lúdico o festivo. En consecuencia, adornarían edificios o construcciones permanentes que se revestirían con estos telones para participar en la transformación barroca, impuesta por la estética engañosa de la fiesta. De igual manera, y en la mayoría de los casos, se utilizarían como elementos de cubrición de arcos triunfales u otros artilugios transitorios. Y, por último, se usarían estas sargas como telones de fondo para las representaciones teatrales, musicales u operísticas.

La importancia de la fiesta durante el traslado de la Corte de Felipe V a Sevilla ya quedó manifestada desde el ingreso de los monarcas en la ciudad, el 3 de febrero de 1729. El ceremonial de la entrada regia supuso un gran despliegue, tanto en la utilización de elementos efímeros como en la ocultación o enriqueci- 
miento de los permanentes ${ }^{1}$. Y, la pintura de sargas con inscripciones, alegorías y ornamentos fue fundamental para este travestimiento urbano.

Sin embargo, no sólo se utilizó este tipo de pinturas en la entrada del monarca, sino que fue uno de los elementos esenciales en la mayoría de las fiestas reales, tanto públicas como privadas, organizadas durante los poco más de cuatro años que permaneció la Corte en nuestra ciudad. Entre los festejos privados, organizados para el deleite y disfrute de los monarcas, los efectuados en los Reales Alcázares tuvieron siempre una especial significación. Incluso, dentro de los mismos, según su carácter cerrado o semicerrado, se establecían diferentes escenarios para su puesta en escena. De esta manera, existiría un ámbito, de carácter más abierto, para la nobleza y autoridades civiles, como es el patio de la Montería; otro, con una connotación más sensorial, que serían los jardines; y, por último, los grandes salones bajos, cuyas limitaciones espaciales incidían en una mayor privaticidad (Lám. 1). Sin embargo, estos salones permitían una doble función: eventos muy selectivos como representaciones teatrales y conciertos, casi para el exclusivo disfrute de la familia real; o bien, la celebración de banquetes y bailes oficiales, con una mayor concurrencia de los altos estamentos sociales.

Como indicamos, los salones bajos de los Alcázares eran utilizados, a veces, para espectáculos. En este caso, documentalmente nos consta la realización de comedias en su interior. Generalmente, estas representaciones teatrales se organizaban coincidiendo con alguna festividad concreta. De esta manera, en un escenario privado se representan comedias que, según la petición del arzobispo Spínola y Guzmán, fechada en Sevilla el 9 de noviembre de 1678, estarían prohibidas para el resto de la población ${ }^{2}$. Este veto, efectivo para el resto del país entre 1720 y 1725 , tuvo algunas fisuras. Razón por la que, en 1729 y 1731, fue ratificada su prohibición tajante en algunos pueblos de la provincia ${ }^{3}$. Sin embargo, según Aguilar Piñal, el traslado de la Corte a Sevilla (1729-1733) implicó la realización en los salones del Alcázar de teatro musical. Así lo demuestran los tres impresos, citados por este autor, de las serenatas escenificadas entre $1731 \mathrm{y}$ 1732, de texto italiano, denominadas: Amor nasce da un sguardo, La regia voscaresccia nella campanna di Tirsi y Gli soni amorosi. Aguilar indica que "son breves coloquios pastoriles con acompañamiento musical" y anota que no

1. MORILLAS ALCÁZAR, José M.a.: La Entrada Triunfal de Felipe V en Sevilla: arquitecturas efímeras y permanentes. Trabajo de Investigación inédito defendido en la Universidad de Sevilla el 18 de julio de 1990.

2. (B)iblioteca (C)apitular (C)olombina (S)evilla: Ms. 63-7-12 (n.o 72). Cfr. este memorial incluido por F. Aguilar Piñal en Sevilla y el Teatro en el siglo XVIII. Cátedra Feijoo. Universidad de Oviedo, 1974, pp. 237-243.

3. AGULAR PIÑAL, Francisco: Sevilla y el Teatro en el siglo XVIII. Op. cit., pp. 18-21. 
poseen un argumento teatral, aunque suponen un primer paso en la reivindicación del espectáculo escénico ${ }^{4}$. Sin embargo, tras el análisis de la documentación que luego analizaremos, consideramos que a pesar de esta postura "oficialista", dicha normativa no fue cumplida en las fiestas privadas de la Corte. Nos basamos, en primer lugar, en el título específico que se da en el manuscrito de "realización de comedias", aunque en la definición oficial se denomine comedia a "toda suerte de poema dramático, que se hace para representarse en el theatro, sea Comedia, Tragedia, Tragicomedia o Pastoral" 5 . Por otra parte, su programación durante las fiestas de carnaval subrayan un carácter más lúdico y festivo. Y, por último, la no existencia de un programa y la no inclusión en el documento del título de la pieza seleccionada, indican la ausencia de publicidad que se quería dar al acto.

En este sentido, en nuestro estudio analizaremos la intervención del pintor Pedro de Peralta en el montaje de la tramoya diseñada, para la representación de comedias en estos salones bajos de los Alcázares sevillanos.

Así pues, según la información documental recabada en el Archivo General del Palacio Real de Madrid, figura la participación de Peralta en los preparativos escenográficos de las comedias organizadas durante las fiestas de carnaval. En la época, este período cronológico se denominaba carnestolendas. Dicho término alude a los tres días festivos anteriores al Miércoles de Ceniza, con el que comienza la Cuaresma. La denominación de carnestolendas, forma plural de carnaval, deriva del nominativo latino caro que significa carne; y de tollere o quitar. Por tanto, textualmente indica "quitar o eliminar la carne".

\section{DATOS BIOGRÁFICOS SOBRE PEDRO DE PERALTA. SU COLABORACIÓN CON FELIPE DIEGO DE CASTRO}

Antes de entrar en el análisis de la documentación, es conveniente incluir algunos datos sobre Pedro de Peralta. Este pintor prestó sus servicios a Felipe V e Isabel de Farnesio durante el traslado de la Corte a Sevilla (1729-1733), participando en las empresas artísticas organizadas por los monarcas ${ }^{6}$.

4. Ibidem, pp. 30-31.

5. Diccionario de la lengua castellana en que se explica el verdadero sentido de las voces, ..., dedicado al Rey Nuestro Señor Don Phelipe V. Imprenta Francisco del Hierro, Madrid, 1726. Tomo Segundo, p. 428. Diccionario de Autoridades. Edición facsímil A-C. Madrid, 1990, p. 428.

6. MORILLAS ALCÁZAR, José María: Empresas artísticas durante la Estancia de Felipe $V$ en Sevilla (1729-1733). Tesis Doctoral inédita, defendida en la Universidad de Sevilla el 17 de septiembre de 1992. Tomo II, pp. 663-667. 
Según Ceán Bermúdez, "Para levantar las Bellas Artes en España Felipe V trajo los mejores profesores de Italia y Francia, estableciendo una junta preparatoria para formar una academia pública en Madrid y envió jóvenes a estudiar a Roma" ${ }^{7}$. De esta forma, Peralta se incluiría en un grupo de pintores, auspiciados por los reyes, que posibilitaron el resurgimiento y la actualización de las artes españolas. En efecto, dada su cotización artística, Sánchez Cantón anota, tras la consulta de los fondos documentales del Palacio Real de Madrid, que este artista fue nombrado pintor de Cámara el 28 de julio de 1731, aunque ya llevaba algunos años realizando estas funciones ${ }^{8}$. Dicho nombramiento se produciría, pues, durante la Estancia de la Corte en la capital hispalense.

Por el contrario, Pérez Sánchez indica que Pedro de Peralta obtuvo la plaza de pintor de Cámara en marzo de $1728^{\circ}$. Sin embargo, no se conoce hasta el momento el documento que pruebe tal cargo. Por ello, suponemos que esta fecha es la correspondiente a su ingreso en la Corte, que coincidiría con el inicio de su actividad pictórica para el monarca, pero no la de su nombramiento como pintor de Cámara.

Por último, Yves Bottineau, reconocido especialista en el arte de la época de Felipe V, ratifica la fecha facilitada por Sánchez Cantón, al fijar el nombramiento de Peralta como pintor de cámara el 28 de julio de $1731^{10}$.

Por otra parte, la actividad desempeñada por este pintor en Sevilla se refleja en un Memorial, fechado el 4 de enero de 1747. En este informe se glosa parte de la trayectoria profesional del artista y se hacen referencias a las actividades realizadas durante el traslado sevillano de la Corte. Textualmente se indica que: "Y haviendo pasado a Sevilla hizo unos Quadros a el olio en pequeño de la Historia de Dn. Quixote en cuia vista y aprovación le confirieron el empleo de Pintor de Cámara". A continuación se menciona la realización de pinturas en los Reales Alcázares sevillanos, indicándose que "pintó el gavinete que se dispuso para la Reina a el temple y en su fachada, que llaman la Varanda, la pintó al fresco" ". Sin embargo, ahora podemos aportar nuevos datos al localizar un

7. CEÁN BERMÚDEZ, Juan Agustín: Diccionario histórico de los más ilustres profesores de las Bellas Artes en España. Real Academia de San Fernando. Madrid, Imprenta Vda. de Ibarra, 1800. Tomo I, p. LIX

8. SÁNCHEZ CANTÓN, Francisco Javier: "Los pintores de los Borbones (II)" en Boletín de la Sociedad Española de Excursiones. Año XXIII, cuarto trimestre. Madrid, 1, diciembre, 1915, p. 282.

9. PÉREZ SÁNCHEZ, Alfonso: "Algunos pintores "rezagados" en el Madrid de Felipe V" en Archivo Español de Arte. Tomo LVIII (N..231). Madrid, julio-septiembre, 1985, p. 216.

10. BOTTINEAU, Yves: El arte cortesano en la España de Felipe V (1700-1746). Madrid, 1986, p. 429.

11. SÁNCHEZ CANTÓN, Francisco Javier: "Los pintores de Cámara de los Borbones (II)". Op. cit., p. 282. 
- documento, fechado en Sevilla en 1732, en el que se reflejan las cuentas de los oficiales de manos para la jornada de Andalucía. En ellas aparecen los nombres de los que "trabajaron en el Gavinete que se hizo en la ziudad de Sevilla para serbirse del la Reyna ntra. sra". Además se incluye el libramiento a D. Manuel de Plazos de 50 reales de vellón para pagar a los distintos maestros y oficiales, y a Felipe Diego de Castro como pintor ${ }^{12}$. En este importante manuscrito se indica que junto a Peralta trabajaron Jean Ranc y el citado Felipe Diego de Castro, escultor que a veces actuaba como pintor. Este gabinete fue ocasión propicia para que Isabel de Farnesio se interesara por algunos de estos artistas y se ocupara personalmente de su promoción, tal es el caso de Castro y Ranc ${ }^{13}$. Y, posiblemente, aunque sin confirmación documental, de Pedro de Peralta.

Especial mención merece Felipe Diego de Castro que efectuó importantes trabajos escultóricos para los monarcas en Sevilla. En este sentido, hemos encontrado abundante documentación. Se trata de otro manuscrito, conservado en el ya citado archivo madrileño, donde se reflejan los artistas que trabajaron en la realización del gabinete de la reina. Aparecen los nombres de Pedro Esteban, aparejador de obras reales; Felipe Diego de Castro, pintor; Pedro de Peralta, pintor; Juan Francisco de Heyra, maestro dorador; Domingo Arias, entallador; y José de Uceda, vidriero ${ }^{14}$.

Así, confirmamos nuestra anterior información sobre Castro, que cultivó al unísono la escultura y la pintura, tal como lo prueba una serie de 29 dibujos autógrafos conservados en la Biblioteca de la Real Academia de BB. AA. de San Fernando de Madrid. Según Bedat, los dibujos se realizaron entre 1733 y 1746, coincidiendo con la estancia del pintor en Roma ${ }^{15}$.

Finalmente, para concluir los datos biográficos sobre Pedro de Peralta, debemos mencionar la relación, fechada el 16 de mayo de 1733. En ella se indica como este artista abandonaba Sevilla, junto a otros compañeros, para trasladarse con la familia real a Aranjuez y seguir desempeñando su cargo como pintor de cámara ${ }^{16}$.

12. (A)rchivo (G)eneral (P)alacio (M)adrid: "Cuenta de los oficiales de manos de la jornada de Andalucía" en Continuación del expediente del viaje a Andalucía del Rey D. Felipe V con su Agusta Real Familia en 1729 a 1733. Secc. Histórica. Caja 213, s/f.

13. BEDAT, Claude: El escultor Felipe de Castro. Santiago de Compostela, 1971, pp. 5-30.

14. A.G.P.M.: "Cuenta de los oficiales de manos de las jornadas de Andalucía". Op. cit.

15. BEDAT, Claude: "Veintinueve dibujos del escultor Felipe de Castro" en Academia. N. 31. Madrid, $2^{9}$ semestre, 1970 , pp. 35-37.

16. A.G.P.M.: Continuación del expediente del viaje a Andalucía del Rey D. Felipe V con su Augusta Real Familia en 1729 a 1733. Op. cit. Caja 213, s/f. 


\section{PERALTA Y LA PINTURA DE SARGAS}

Además de las obras descritas anteriormente, nos consta que Peralta realizó, sobre sargas, los telones o decorados para una serie de comedias interpretadas, con motivo del carnaval de 1732, en el salón bajo del Alcázar de Sevilla. Este tipo de farsas se solían escenificar el martes de carnaval y eran uno de los divertimentos favoritos de los reyes y príncipes. Se celebraban en los grandes salones palatinos, ante un reducido número de invitados, y de aquí su carácter marcadamente elitista.

En la documentación consultada, expresamente se indica que este teatro se realizó para el esparcimiento de los príncipes de Asturias, D. Fernando y Da María Bárbara de Braganza (Lám. 2). Se trata de un manuscrito que refleja una relación de gastos, redactada y firmada por el propio pintor. En ella se indica que es una: "Memoria de lo que se a gastado en el theatro que se a echo para el Serenísimo Sr. Príncipe de Asturias, mi amo, por orden de el Sr. D. Joseph de Losada, maiordomo de Su Alteza". Se anotan, expresamente, los materiales usados por el pintor, las cantidades de los mismos y el lugar donde se efectuó esta pintura decorativa. En este sentido, textualmente se reseña que Peralta pintó "todos los lienzos, bambalinas y frontis que componen el teatro". Para ello, usó ciento treinta y cinco baras de lienzo y trescientos ochenta cartones. Además de engrudo, cola fuerte, papel de estraza y colores para pintar. El artista necesitó para finalizar su labor veintiséis días de trabajo continuado ${ }^{17}$.

Del documento se desprende que esta pintura sobre sargas se dispondría formando un frontispicio o frontis, entendiéndose por tal la fachada anterior o decorado, que serviría como telón de fondo en la representación. Dentro de él, las bambalinas según el concepto de la época eran "unos pedazos de lienzo pintados, que en los theatros donde se representa se ponen de bastidor a bastidor, con cuya pintura se finge lo superior de lo que la mutación imita aire, fuego, cielo, etc." ${ }^{18}$. Sin embargo, al no existir referencias directas a la temática de esta pintura efímera, no podemos aventurar hipótesis sobre ella. No obstante, parece probable la inclusión de dos zonas perfectamente diferenciadas: la superior o aérea y la inferior o terrestre.

En cualquier caso, sea cual fuere el asunto pictórico desarrollado, Heers indica que en las fiestas de carnaval las farsas más usuales eran las alegorías de las virtudes, los juegos de corte, las sátiras conyugales, y las disputas entre personajes populares ${ }^{19}$. Por tanto, las principales composiciones decorativas se-

17. A.G.P.M.: "Cuenta de algunos gastos sueltos de la jornada de Andalucía de 1730 a 1733. Caja 213. Op. cit., s/f.

18. Diccionario de Autoridades. Op. cit. Tomo III, p. 541.

19. HEERS, Jacques: Carnavales y fiestas de locos. Barcelona, 1988, pp. 201-220. 
rían para las alegorías y juegos cortesanos, los llamados jardines de Venus o galantes; para las costumbres amorosas, los interiores domésticos; y para el dialogo entre personajes populares, los exteriores urbanos.

Sobre la cantidad de lienzo utilizado para componer el escenario del teatro, se indica que fueron necesarias 135 baras de lienzo. Según la equivalencia en metros de la bara castellana, el total ascendería a 101,25 metros. Sobre los cartones se expresa que se dispusieron 380. Cartón en la época hace referencia a una serie de paneles, de este material, que se dispondrían sobre el escenario para ambientar la pieza teatral representada. De esta manera, podemos imaginar la gran magnitud y variedad que tendría esta escenografía.

Por último, sólo nos queda reseñar que, tal como indica Heers, el carnaval es la fiesta de la abundancia y de la transgresión en la que se produce un gusto por el exotismo y las imágenes fantásticas ${ }^{20}$. De esta forma, el traslado de la Corte de Felipe $\mathrm{V}$ a Sevilla supuso encontrar un escenario perfecto, en los Reales Alcázares, para el divertimento y distracción de la familia real y, especialmente, del monarca. A lo anteriormente reseñado debemos añadir una amplia serie de celebraciones festivas, programadas para combatir el carácter depresivo del rey ${ }^{21}$.

20. Ibidem, p. 205.

21. MORILLAS ALCÁZAR, José María: Empresas artísticas durante la Estancia de Felipe $V$ en Sevilla (1729-1733). Op. cit. Tomo I, pp. 474-590. 


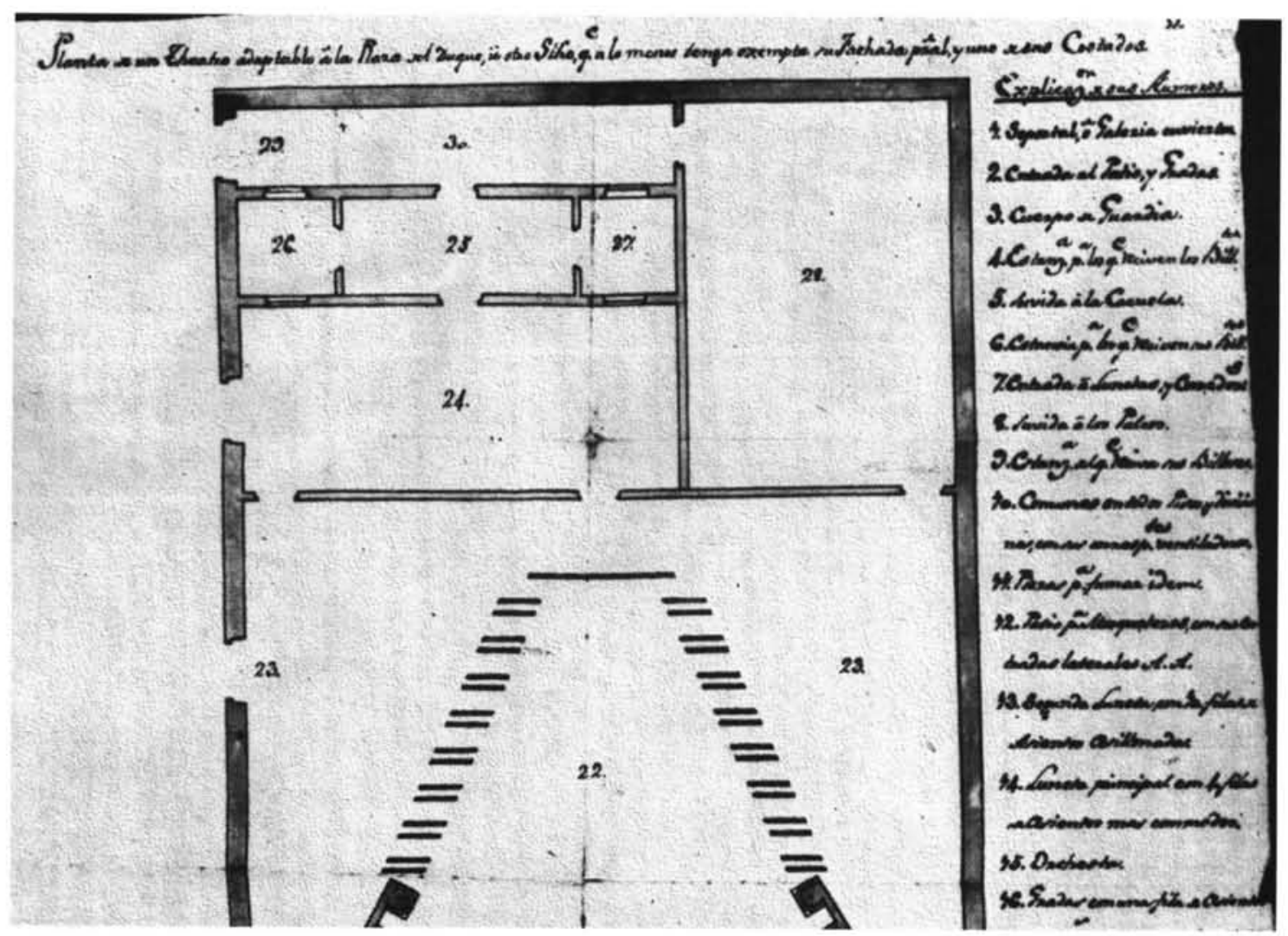

Lám. 1

Grabado del Patio de la Montería de los Reales Alcázares de Sevilla, escenario de las grandes celebraciones festivas del siglo XVIII. 


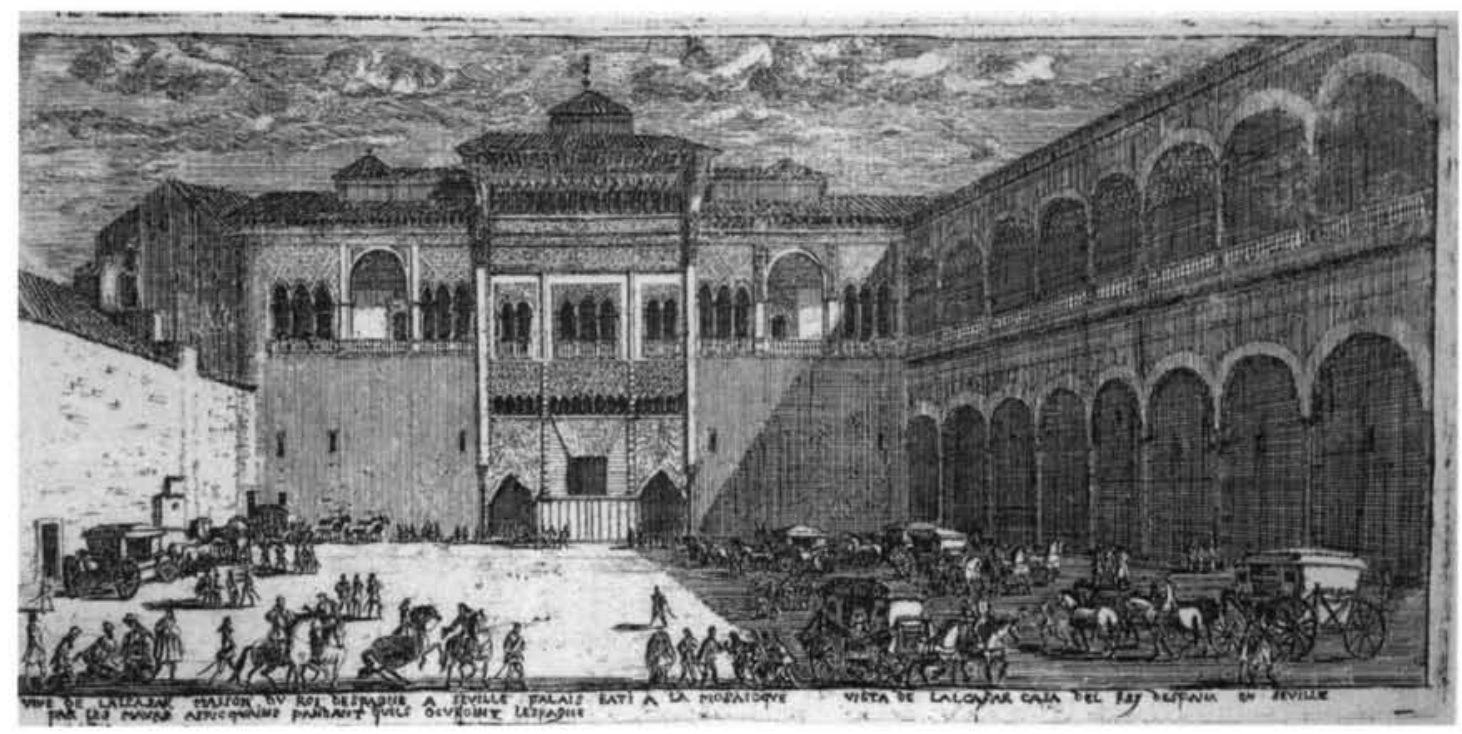

Lám. 2

Planta del Teatro Cómico de Sevilla (Félix Caraza, 1794), publicada por Aguilar Pinal en Sevilla y el teatro en el siglo XVIII. La disposición trapezoidal que adopta la escena o proscenio deriva de la colocación de las butacas para la familia real y personalidades de la Corte en las representaciones teatrales, escenificadas en los salones interiores de los palacios. 